\title{
On the Interaction Between Media and Economic Development--Analysis based on the Principles of Western Economics
}

\author{
Qian Xue \\ College of Finance and Economics, Tibet University, Lhasa 850000, Tibet Autonomous Region, China
}

\begin{abstract}
In the context of the era of big data, the cultural industry represented by media is developing rapidly and gradually becoming an important force to promote economic growth. Based on the relevant principles of Western economics, the article first analyzes how economic influence guides media activities from the perspective of media and audiences. Secondly, it explores how to promote economic and social development through media from the perspective of media's allocation of production factors, which provides a theoretical basis for scientifically understanding and understanding media economy.
\end{abstract}

Key words: Media economy; Resource allocation; Media industry

Publication date: April, 2021; Publication online: 30 April, 2021

*Corresponding author: Qian Xue, 2534281669@.qq.com

\section{Introduction}

On June 21, the "9th Media Development Forum and 2018 Media Blue Book Release Conference" was held at Tsinghua University. At the meeting, the editor-in-chief of "Media Blue Book" and Professor Cui Baoguo of Tsinghua University pointed out that the digital economy is sweeping the world, with the rapid development of the Internet. With development, the structure and classification of the media industry have been overturned and reconstructed time and time again. With the deepening of the integration of the Internet and traditional media, the media industry has become an important part of China's digital economy. China's economy is progressing steadily. The continuous growth of Chinese consumer consumption and the steady increase in cultural media consumption have driven the continuous growth of the media industry. The current "media" is a comprehensive concept, including all kinds of media devices, as well as various forms of media or media organizations, as well as content production and data storage institutions. It is a comprehensive system. The media mainly monitors the social environment, coordinates social relations, inherits culture, and provides entertainment. As a representative of the cultural industry, the media industry has made significant contributions to promoting economic growth, creating wealth, increasing employment opportunities, and improving the country's soft power.

Different economic theories and analysis methods form the theoretical basis of media economics. Media economics mainly studies how economic and financial forces affect the media system and media organization, and its essence is the influence economy. Influence is the most valuable internal quality of the media, which enables the effective combination of economic and social benefits of the media. Based on the research of existing literature, the article raises two questions: First, how does economic influence guide media activities? Second, how does the media promote economic development? Based on previous research results, the above two issues are explored through the relevant principles of Western economics, so as to deepen people's understanding of the media economy, provide a useful reference for the development of the media economy, and enrich the content of my country's media theory.

2 The guiding role of the economy in media activities 


\subsection{The guiding role of the media}

Media refers to the carrier of disseminating information and consulting information. Newspapers, magazines, radio and television are the traditional four major media. With the development of science and technology, new media, such as Internet media, have gradually emerged. As a producer of media content, media companies obtain profits by providing content to customers, packaging the content into intellectual property rights for external sales. Economic globalization has accelerated the development process of the information age. In the context of the era of big data, traditional media are facing unprecedented shocks, and it is urgent to accelerate the transformation of the media industry. The advancement of science and technology and the development of media integration have caused earth-shaking changes in the audience's usage habits of media products and media business models ${ }^{[1]}$. The development level of the media is positively correlated with the regional economic level ${ }^{[2]}$. The goal of media organizations is not only to maximize profits, but to pursue quality and realize the value of "public service" is its ultimate goal. The media market is a typical oligopoly market, and the behaviors and decisions of enterprises are typical strategic behaviors and strategic decisions. Market competition is intensifying, and achieving a win-win situation and cooperative gaming is the key to the sustainable development of the media industry. Competition urges media organizations to start rent-seeking activities in order to obtain monopoly status and monopoly profits. Rent-seeking activities can lead to inefficient resource allocation and cause serious economic losses. This requires the government to intervene in monopoly behavior. The government can effectively supervise monopoly prices and monopoly production, and at the same time provide financial subsidies for the losses of monopoly manufacturers caused by monopoly control ${ }^{[3]}$.

\subsection{The guiding role of the audience}

Media products have dual attributes, which are both private and public. The market mechanism is mainly used to regulate private goods. Since the "free rider" phenomenon in public goods is more common, the government must assume the responsibility of regulating public goods. The output and demand of media products cannot be determined by individual decisions in the market, but must be determined by the government using cost-benefit analysis methods. If the revenue of a media product is greater than or at least equal to its cost, it is worth producing ${ }^{[3]}$. As a commodity, its value is a combination of social and economic benefits. The use value is realized through audience reading. Most media organizations have formed an audience-centric business model, and the audience's attention resources are the real value. Economic development has increased the cultural consumption level of users, has led to diversification of cultural needs, and has prospered the media market. The media market is flooded with all kinds of media, and the audience's choices are more diverse. The pursuit of maximum utility is the behavior goal of the audience. Consumers should equalize the marginal utility of the last dollar they spend on each commodity purchase, so as to achieve the maximum utility under the given income, price and preference conditions ${ }^{[3]}$. Considering consumers' optimal purchase options and optimal purchase product combinations, this requires media organizations to produce heterogeneous products to meet consumers' different utility needs, and content is the key to winning in market competition. The audience's consumption of media products realizes the value compensation for media content. The value realization degree of media products should be measured by the Pareto criterion. Pareto optimality should be considered in the production and exchange of media products, so that the economic efficiency can reach the optimal state. Competition in the media market has become more intense, and audience experience and evaluation have become the focus of media organizations. With the gradual deepening of media convergence, customized services centered on audiences are favored by emerging media. Economic development has promoted the development of emerging media, and has unblocked communication channels with users, making it easy to understand and meet the needs of audiences in a timely manner.

\section{The media's mechanism for economic development}

3.1 The development of the media can activate the market economy and optimize the allocation of resources.

The media economy has become an important industry of the national economy. The biggest feature of the media industry is the high initial cost, the content cannot be consumed, and the low copy cost. Media products do not meet the premise of resource scarcity in economics. 
Products are not exhausted after being consumed. Therefore, budget constraints and optimal allocation of influence resources and attention resources are the focus of media economic analysis. The consumption of media products must reach a considerable scale in order to achieve optimal economic benefits. How to minimize cost and maximize output is a key issue that enterprises should consider. Enterprises can expand the scale of production to increase economic efficiency, that is, economies of scale, but the expansion of production to a certain scale will cause diseconomies of scale. Enterprises must grasp this metric well. Due to the high initial cost, media organizations cannot simply rely on their own expanded reproduction to supplement media input, and need to absorb foreign capital to inject into the media industry's operations. Oligopoly is the most common market structure in the media industry. In an oligopolistic market, the behaviors of manufacturers influence each other. The marginal cost is always less than the average cost. The more audiences, the lower the average cost and the higher the marginal revenue, which can achieve economies of scale and obtain higher profits. In order to reduce transaction costs, companies can share specialized resources and professional skills, diversify operations, diversify risks, and give play to the advantages of economies of scope. The learning effect of learning by doing and the economies of scale can reduce the long-term average cost of enterprises. The basic law of short-term production is the law of diminishing marginal returns. Enterprise production should control the output at the point of maximum reward, that is, when the marginal output is equal to the average output. In the long-term production process, at first the enterprise faces the stage of increasing returns to scale; continuing to expand the scale, staying at the stage of constant returns to scale; further expanding the scale of production, it will enter the stage of diminishing returns to scale. While enterprises use economies of scale to reduce costs, they should also consider the issue of returns to scale and grasp the metrics. The Cobb-Douglas production function can explain this problem well[3].

\subsection{The development of the media industry can expand employment and promote the transformation of economic structure}

Technological factor owners obtain income by investing technology in production and business activities. In today's era of knowledge economy, the widespread attraction of high-tech talents is of great significance to my country's development of high-tech industries. Through horizontal expansion and vertical expansion, media organizations expand total investment and market share, increase media influence, help the development and application of new technologies, attract high-quality talents, increase employment opportunities, and develop new business models to improve the realization of media content and ability to accelerate the return of funds. With the expansion of production scale, enterprises can use more advanced technology and machinery and equipment to make the division of labor within the enterprise more reasonable and professional. Producers can maintain a specific output by substituting the two elements for each other, that is, marginal technology substitution. Taking capital and labor as an example, increasing labor input can appropriately reduce capital input, which not only saves money, but also creates more employment opportunities for laborers. However, under the premise of maintaining the same output, the amount of labor input is increasing, and the amount of capital that can be replaced is decreasing. Learning by doing means that workers, engineering and technical personnel, and production managers obtain production skills and knowledge from experience. Learning by doing can reduce the long-term production cost, which is called the learning effect. Opportunity cost is also an important link in production costs. Opportunity cost enables producers to transfer economic resources from low-income production to high-income production ${ }^{[3]}$. The competition between companies has prompted them to cater to the tastes of mainstream audiences. The product content is the same. The marginal utility of homogeneous content to consumers is gradually diminishing, which can also lead to rejection of the audience and loss of welfare. Producing heterogeneous products, cultivating an influential economy, and establishing reputation and brand are the magic weapon to win. The development of the media has promoted the development of the information industry, promoted the transformation of my country's economic structure to a knowledge-based economy, presented a diversified trend, guided the trend of consumption, brought faster and more convenient economic life, and created a lot of profits and taxes for China.

\subsection{The media can narrow the information gap and}




\section{improve overall economic efficiency}

Information is also a very valuable resource, and its value can be evaluated by expected benefits. Information can improve the utility and profit of an enterprise, reduce the risk and error of the enterprise's decision-making, thereby increasing the expected return. Information asymmetry makes the transaction cost between the market and the enterprise significantly different. Enterprises can use economies of scale and scope to complete part of market transactions within the enterprise, thereby eliminating or reducing the high transaction costs of some market transactions. Under the condition of incomplete information, if an enterprise wants to develop sustainably, it should replace profit maximization with the goal of maximizing sales revenue or maximizing market share. In the case of incomplete information and asymmetric information, the market mechanism can only solve part of the problem of information mismatch, which can also be solved by establishing "reputation". In the case of insufficient information, the market will be flooded with low-quality products, and reputation can help consumers distinguish between good and bad markets and choose high-quality products. Reputation increases the benefits of companies choosing honesty, and at the same time increases the cost of corporate fraud. It is also necessary for the government to regulate information to ensure that consumers and producers can obtain sufficient and accurate information and increase the "transparency" of the market. The media can spread information between audiences, enabling both parties to "know the world without going out" to make the right choice and avoid waste of resources. Technological advancement has made direct payment possible, making it easy for producers to fully understand consumers' consumption preferences and realize the use of consumer surplus. Using this part of consumer surplus can provide products that satisfy the taste of non-mainstream audiences and increase social welfare. The media maximizes the efficiency of market operations, optimizes resource allocation, and significantly improves overall macroeconomic efficiency.

\section{Conclusion}

The development of media economics provides valuable theoretical guidance for the media industry. The relevant principles of media economics can explain media activities well. Economic development has promoted technological progress, brought people a more convenient life, enriched consumption, and invigorated the market, thereby promoting the development of the media industry. The reform of the media has provided more opportunities for economic development, provided more employment opportunities for workers, optimized resource allocation, and improved overall economic efficiency. While enjoying the convenience brought by the media and economic development, we should not ignore the problems that exist and cause during the development process. As a representative of the cultural industry, the media industry guides the development of culture. As a country's cultural soft power, culture is playing an increasingly important role in international competition. While we are developing, we should also prevent criminals and other countries from using cultural forces to infiltrate our country and attempt to dismember our culture. The adverse effects of the monopoly of the media industry cannot be ignored. Monopoly is not conducive to cultural exchanges and progress, and should encourage the cultural market to flourish. Other scholars can provide meaningful suggestions for related research.

\section{References}

[1] Hang M, Zhou CC. Competition and game: Media economy and media management in the digital era[J]. Theoretical Frontiers, 2019, (5).

[2] Wang XY, Guo LH. Research on media reform and media economic development [J]. Modern Communication, 2019, (1).

[3] Gao HY. Western Economics (Micro Part) Fifth Edition [M]. Beijing: Renmin University of China Press, 2011. 